\title{
Sport participation and positive development in older persons
}

\author{
Joseph Baker • Jessica Fraser-Thomas • \\ Rylee A. Dionigi • Sean Horton
}

Received: 26 January 2009/Accepted: 23 November 2009/Published online: 9 December 2009

(C) European Group for Research into Elderly and Physical Activity (EGREPA) 2009

\begin{abstract}
In many Western countries, more and more people are living longer. As part of this demographic shift, increasing numbers are participating in Masters sport. In the past, sport was considered important for the development of young people; however, the potential for sport participation to affect positive development across the lifespan is now recognized. The purpose of this paper is to introduce conceptual frameworks from developmental psychology that are being used to understand youths' positive development through sport, and to explore these frameworks in the context of sport as an avenue for positive development in older persons. To achieve this aim, we outline research on sport participation as it applies to youth development and consider relevant aspects as they broadly apply to development later in life. This discussion highlights the inherent paradox of sport participation-that it has the potential to provide considerable positive growth but also the potential for significant negative consequences. Finally, we explore areas of future research related to positive development in older persons through sport.
\end{abstract}

Keywords Masters athlete $\cdot$ Health $\cdot$ Age

J. Baker $(\bowtie) \cdot$ J. Fraser-Thomas

School of Kinesiology and Health Science, York University, 4700 Keele St,

Toronto, ON M3J 1P3, Canada

e-mail: bakerj@yorku.ca

R. A. Dionigi

School of Human Movement Studies, Charles Sturt University,

New South Wales, Australia

e-mail: rdionigi@csu.edu.au

S. Horton

University of Windsor,

Windsor, Canada
One of the most robust and intriguing trends over the past century and a half is the consistent increase in the human lifespan. From 1840 to the present, lifespan has increased 3 months each calendar year, to the point where children born today in the most advantaged countries in the world can expect to live upwards of 80 years [1]. Putting the obvious benefits of longer life aside, such longevity poses certain challenges from both an individual and societal perspective. The leading edge of the 'baby boom' generation are now entering their 60s in North America [2] and in other developed countries the 'senior' population is increasing dramatically. This trend will continue for the next 20 years [3]. In 2006, the Heart and Stroke Foundation of Canada expressed concern with this demographic shift, particularly considering the poor health of many in the baby boom generation. Their report indicated that $52 \%$ of boomers are sedentary and $30 \%$ are obese, and that both of these numbers had increased dramatically in the last 10 years. The Heart and Stroke Foundation called for a national strategy in Canada that would increase levels of physical activity in this cohort, and across the entire population. Similar strategies have been advocated in the United States and Australia. For example, the Active Australia campaign was launched by the Australian Sports Commission in 1996 to promote participation in sport and physical activity as part of a strategy to improve overall health outcomes [4]. In 2001, the Australian Sports Commission and the Department of Veteran Affairs produced the Older, smarter, fitter document as a guide for providers of sport and physical activity programs targeting older Australians [5]. In the United States, the American Association of Retired Persons et al. developed the National blueprint for increasing physical activity among adults aged 50 and older in response to the economic and social concerns of an 'unhealthy' aging population [6]. 
While many people accept the health benefits of exercise, this acceptance does not always equate to regular involvement. For example, Ory, Hoffman, Hawkins, Sanner, and Mockenhaupt [7] noted that 98 percent of adults over the age of 50 recognize the importance of physical activity to maintaining health, yet only a small minority of these adults meet the minimum daily physical activity recommendations [8], as participation in sport and physical activity tends to decrease with age [4, 8, 9]. This gap between what people know to be important and their actual health behaviors remains a critical concern for researchers and policy makers alike.

Given the negative stereotypes towards aging and the elderly that prevail in Western society $[10,11]$, perhaps the tendency of seniors to avoid physical activity and sport is not overly surprising $[12,13]$. Certain studies suggest that seniors themselves internalize these negative attitudes and stereotypes [14], which in turn influence their decisions to partake in physical activity, sport, and other healthpromoting behaviors [13, 15]. In particular, evidence suggests many older women believe activities that involve exertion and are physically fatiguing are too risky for their health; consequently, they tend to avoid sport and exercise [16-18].

Seniors who stay active above and beyond recommended levels may perform an important social role, as they can alter societal expectations of what it means to grow old. For example, Ed Whitlock, at age 69, set a world record for being the oldest person to run a marathon in less than 3 h. [19] Now 75, Whitlock has the only three sub-3-h performances by a septuagenarian [20]. Considering that in 1908 the world record for a man of any age was 2:55 h, Whitlock's accomplishments seem all that much more impressive. Older athletes, like Whitlock, appear to be a somewhat select or privileged group who possess the time, ability, health, desire, and disposable income to regularly train and travel to sites of competition. Nevertheless, older athletes have become an identifiable (and growing) group in contemporary Western society whose experiences and lives we know very little about [21].

Past research has focused primarily on the health benefits of seniors' involvement in physical activity, with significantly less research focused on outcomes associated with older persons' participation in organized sport [21, 22]. This trend mirrors research in younger populations. While studies outlining the benefits of physical activity to children and adolescents' health and wellbeing are well documented [23], much less empirical research has focused on the physical and psychosocial outcomes associated specifically with sport participation [24]. However, with the emergence of psychology research focused on 'positive psychology' and 'positive development' [25], several conceptual frame- works are currently being used to study children's positive development through sport [26].

Although researchers examining human development have typically focused on youth populations, development occurs across the lifespan [27]. In the past, developmental theorists argued that growth and character building happened primarily in childhood and adolescence; hence, sport was considered important for young people and not necessary for older people [28]. More recently, however, many have argued the potential benefits of leisure involvement to healthy development in later life [29, 30]. In particular, sport participation is now promoted to older people as a means to maintain their health and wellbeing. Given that the surge in retiring baby boomers may lead to a significant increase in the number of older adults participating in Masters sport [21], the physical, psychological, and social outcomes of sport for older adults are worth examining [12, 31, 32]. Masters sport is a unique context that provides opportunities and outcomes that extend beyond regular involvement in physical activity, such as walking or doing an exercise class. Masters sport allows older people to regularly compete against others within a similar age range in a variety of individual and team activities. Competitions range from weekly occurrences in one's locality to major national and international multi-sports events that are held every 2 or 4 years, respectively, in different countries. Despite competition being inherent in Masters sport, the core values and social discourses underpinning this movement are participation for 'fun, friendship and fitness' [21], which is quite similar to how youth sport is framed (i.e., it is often assumed that children play sport to have fun, make friends, and keep fit). The purpose of this paper is to introduce conceptual frameworks from developmental psychology that are being used to understand youths' positive development through sport, and to explore these frameworks in the context of positive development in older persons through sport. We acknowledge that there are quite distinct differences between younger and older people from a developmental perspective; however, in applying such models to the specific context of sport participation, there appears to be similar outcomes experienced, regardless of age. In the sections that follow, we outline research on sport participation as it applies to youth development, consider relevant aspects of youth development as they broadly apply to development later in life, and explore areas of future research related to positive seniors' development through sport.

\section{Positive youth development}

Positive youth development research emerged from practitioners' and researchers' growing concern for the health 
and wellbeing of adolescents. In the past, the approach to dealing with adolescent problems and issues was a topdown "deficit reduction" approach [33], where the problem was identified (e.g., childhood obesity) and funding was provided to address the problem. However, as Pittman [34] pointed out, youth who are "problem free" are not necessarily "fully prepared" to be engaging and contributing members of society. As such, positive youth development research generally applies a bottom-up "asset-building" approach to youth development, where youths' strengths are identified and built upon [33].

Youths' extra-curricular activities have been proposed as tools through which positive youth development can be fostered [35]. Sport, as the most popular type of youth program, [36, 37] has been of particular interest to developmental and sport psychology researchers alike. In recent years, numerous studies have examined varying aspects of youth development, some of which have obvious application to older persons. Of particular interest in this paper are studies suggesting that sport participation provides something meaningful and meritorious above and beyond that achieved through regular, non-competitive involvement in physical activity.

\section{Qualities related to sport participation in youth}

Sport participation is often extolled as an optimal avenue for the development of positive characteristics like sportspersonship, fair play, empathy, and graciousness [38]; however, there is very little empirical research examining the evidence for this position. There is abundant research (both quantitative and qualitative) on the associations between sport participation and qualities such as moral values, moral reasoning, and sportspersonship; however, prior work in this area has been drawn largely from crosssectional designs which do not allow for an identification of cause and effect [38].

Lerner, Fisher, and Weinberg [39] advocated that youth activities (including sport) should emphasize the development of the 5 Cs: competence, character, connection, confidence, caring/compassion. They suggest that if these five desired outcomes are fostered in youth, youth will in turn develop into contributing members of society (the sixth "C"). Specifically, youth will give back to society and contribute to the positive development of the next generation of youth.

Similarly, Benson and colleagues [33, 40-43] developed a list of core developmental processes, resources, and experiences for children and adolescents based on scientific literature and practitioner's wisdom. These 40 developmental assets are divided into two broad categories (external and internal assets), and further divided into eight sub-categories (support, empowerment, boundaries and expectations, constructive use of time, commitment to learning, positive values, social competence, and positive identity). Examinations of these assets have confirmed their role in preventing negative outcomes in youth development (e.g., [41]) and promoting positive outcomes [e.g., [42]]. Fraser-Thomas and her colleagues [24] noted that sport is an ideal activity for the development of many of these assets. In particular, sport programs appear to be unique from other extra-curricular activities (including unstructured physical activity), given sport programs' facilitation of several key developmental attributes (e.g., goal-setting, effort, time management, emotional regulation, physical skills, teamwork, social skills, leadership, diverse peer relations). A recent qualitative study examining adolescents' positive and negative developmental experiences in competitive swimming [44] pinpoints some of the mechanisms and processes by which youths' positive development may be occurring. In particular, swimmers highlighted how the time and effort required to achieve results (e.g., early morning practices, volume and length of practices, intensity of training camps) and the sport's focus on self-improvement (e.g., personal best times, graded time standards) contributed to their development of a strong work ethic, commitment, discipline, and perseverance. Findings suggesting that sport may also foster negative experiences are of some concern; however, recent work [45] proposes that negative experiences such as stress can lead to positive development as adolescents learn how to overcome issues, a notion that is further explored in the next section.

Positive youth development through growth experiences

A critical component of positive youth development seems to be involvement in experiences that challenge or 'stretch' the participant's abilities. Through focus groups with adolescents highly involved in school and communitybased extra-curricular activities (e.g., sports, arts, clubs), Dworkin, Larson, and Hansen [46] explored youths' growth experiences, defined as "experiences that teach you something or expand you in some way, that give you new skills, new attitudes, or new ways of interacting with others" (p. 20). Six key areas of growth experiences were outlined: (a) identity, (b) initiative, (c) basic skills, (d) interpersonal relationships, (e) teamwork and social skills, and (f) adult networks. Of interest, follow-up research led to the identification of negative experiences in extracurricular activities in five areas: (a) stress, (b) negative peer interactions, (c) social exclusion, (d) negative group dynamics, and (e) inappropriate adult behavior [47].

Hansen et al.[48] examined the growth experiences of American high school students in five activity categories (i.e., sports, faith-based/service, academic/leadership, per- 
formance/fine arts, and community/vocational) and noted that although adolescents involved in sport activities reported moderately high rates of growth experiences in some areas (i.e., self-knowledge, goal-setting, effort, time management, emotional regulation, physical skills, teamwork, social skills, leadership, and diverse peer relations), they also reported the highest rates of negative experiences in all areas (i.e., stress, negative peer interactions, social exclusion, negative group dynamics, and inappropriate adult behavior). These results highlight the inherent paradox of sport participation - that it has the potential to provide considerable positive growth but also the potential for significant negative consequences.

\section{What does sport develop in the older participant?}

Masters athletes are unique because they continue to train and compete well into old age. It appears that this continued involvement in sport has its benefits. Sport scientists $[19,49,50]$ have suggested that prolonged training by Masters athletes plays a critical role in the maintenance of athletic performance even in the face of predicted agerelated decline. The physiological changes that occur with age are well documented - age changes for maximal heart rate [51] and aerobic capacities [52-54] are significant. Yet, age-related physiological decline is not as severe in Masters athletes.

Pollock et al. [55] investigated the aerobic capacity and body composition of Masters track athletes and evaluated the relationship to age and maintenance of training over a 10 -year period. Competitive athletes who maintained their training intensity over the 10 -year period prior showed no significant changes in aerobic capacity, whereas individuals who reduced their training intensity showed a significant decline. A similar study by Hagberg et al. [51] compared older elite runners to their sedentary peers and to younger elite runners. The older sedentary subjects exhibited a maximal oxygen uptake that was $47 \%$ lower than Masters athletes'; furthermore, most of the difference between Masters athletes and younger elite runners was attributable to the lower maximal heart rate exhibited by the Masters. Combined, the results from Hagberg et al. and Pollock et al. demonstrate that maintaining training intensity helps individuals sustain a higher level of aerobic performance with aging.

Much of the evidence pertaining to Masters athletes illustrates they are the physical elite and 'best preserved' of their age cohorts; however, these examinations have been largely physiological in nature. A more critical question for the current review is whether involvement in Masters sport provides additional psychosocial benefits akin to those suggested for youth involvement in sport and whether those effects go beyond those derived from general engagement in physical activity. There is a paucity of research considering this issue; however, the results have been largely consistent and provide a fertile ground for further work in this area. The following discussion suggests sport participation can facilitate positive development in older adults by negotiating the aging process, providing continued motivation for physical activity, and challenging age-related stereotypes.

Helps negotiate the aging process

Qualitative research by Dionigi [21, 22, 31, 56, 57] highlights how sport participation can assist the management of an aging identity. Dionigi conducted short semi-structured interviews with 110 Masters athletes (aged 55-94; even gender split) at the Eighth Australian Masters Games and held in-depth interviews with 28 athletes (15 women, 13 men, aged 60-89) who had competed in these Games. The themes to emerge from this research were common across participants, regardless of individual differences (i.e., age, gender, team sport or individual event, exercise history). Discussions with these older athletes about why they compete in sport and what it means to them revealed that participation in Masters sport was a key strategy for negotiating the aging process. The participants' words and actions relating to the management of aging reflected two broad (interacting) themes: "I'm out here and I can do this!" and "Use it or lose it."

"I'm out here and I can do this!" describes how the older participants in Dionigi's study perceived themselves as 'an exception to the rule.' That is, they set themselves apart from 'other' inactive older people and expressed pride in the belief that they were different to the 'stereotypical' older person (i.e., someone who is frail, dependent, lonely, ill, and most likely living in an aged care facility). Many felt that competing in Masters sport kept them "young" because they were connecting with and competing against younger people, maintaining physical, mental, and social health, and were fully engaged in life. For the majority of participants, "the satisfaction of knowing that [they were] not losing it" was extremely important. In other words, by monitoring their performance in the context of sport, the participants demonstrated that "I can still do it [i.e., compete]! I'm not too old." In particular, some participants described how they challenged themselves and pushed their body to its limit in order to get the greatest health benefits from their sport participation. These feelings of strength, confidence, and competency generalized into an overall perceived sense of control and independence, which was encapsulated in the common phrase, "I can do everything I want to." All of the above feelings and experiences indicated to the older athletes (and others) that they were adapting to the aging process and not yet experiencing ill health, disability, isolation, or dependency in old age. 
As a result, the participants expressed a sense of personal empowerment and control over their body and lives that they saw as direct benefits of their involvement in competitive sport. This finding highlights that their sport participation is (in part) a story of resilience, enthusiasm, pride, determination, lives well lived, and lives lived to their potential. Furthermore, the older athletes constructed and perceived themselves as a person of 'social worth' who is conscientious about maintaining good health, helping to reduce health care costs, capable of success in competition, and deserving of public recognition.

On the other hand, the "Use it or lose it" theme points to the tenuous nature of these feelings of competency, connectedness, confidence, satisfaction, and personal empowerment and highlights the many concerns older people express about aging. All of the participants in Dionigi's study indicated a desire to fight the aging process (i.e., use their mind and body as much and for as long as possible) by remaining competitive in sport. In the words of the participants, they were strongly motivated by the concern that if they stopped being active through sport they will become "old," "rusty," "age badly," "dependent on others," or "end up in [an aged care] home." Underlying their participation in sport were beliefs that they were "making these latter years as enjoyable as [they] can by keeping fit" or "setting [their] own quality of life by being fit and active." These findings are supported in other work examining older persons' sport participation. For example, Max, an 88-year-old runner from the study by Roper et al. [58] said that his competitive running career was predominantly linked to leading a healthy lifestyle. Similarly, Phoenix and Sparkes [32] found that for Fred, a 70-year-old Veteran football/soccer player, "being fit and healthy" was a key factor in his construction of a positive aging identity.

Many older athletes believe that if they lose their "physical ability," they will also lose their independence, health, sense of control over their life, and sense of self. Many older athletes recognize that fragility, dependency, and illness are possible outcomes of long life. Simultaneously, however, they express the undesirability of these 'risks' and believe that one should attempt to delay their onset for as long as possible-with competitive sport being one practice to avoid or delay these potential threats. For some participants, this meant they were "turning a blind eye" to the possibilities of aging by remaining extremely active and competing in sport until a factor beyond their control stopped them. A minority of participants said that they would rather "die on the court" or in the field of play in an attempt to avoid ill health and dependency in old age altogether. The majority of participants, however, adopted the "it's life" attitude and spoke of the necessity to "keep going" for as long possible in order to make the most out of life in the time that remained. As one female athlete said, "keep battling on...you have just got to face life and make the most of it." This latter finding indicates an acceptance of aging and a return to the idea that these individuals are adapting to the aging process by experiencing a sense of challenge, growth, and enjoyment in the context of sport (and beyond). Evidently, sport can help older persons fight/ resist, monitor, adapt to, avoid, and/or accept the aging process. In other words, participation in sport has the potential to assist in the process of negotiating an aging identity.

\section{Provides continued motivation for physical activity}

Given the robust relationship between continued involvement in physical activity and maintenance of physical and cognitive functioning [59], possession of an adaptive exercise motivational profile is a desirable quality for older persons. Motivation research conducted on Masters athletes thus far suggests they participate in sport for many reasons, including enjoyment, desire for personal achievement and winning, social affiliation and recognition, and health and fitness reasons [60]. The accumulated findings provide valuable insight into the motives behind Masters athletes' participation. The conclusions are limited, however, because most studies were exploratory in nature and conducted mainly in recreational rather than competitive sport settings. For instance, a recent study [61] found that recreational Masters marathon runners reported a greater degree of functional commitment, which was related to feelings of satisfaction and opportunities associated with participation in Masters sport (e.g., health or social benefits). Findings from a review of the literature on the motives and perceived benefits of older persons' involvement in competitive (rather than recreational) sport by Dionigi [22] suggest that Masters athletes have an adaptive motivation profile for continued physical activity. However, additional research in this area is critical.

The nature of a Masters athlete's commitment can be derived from the persistence of behavior motivated through either volitional feelings of personal preference or a sense of external control and compulsion [62]. Scanlan et al. [63] suggested that there were two major reasons why an individual would commit to sport participation, 'because they want to' continue participating and 'because they have to'. Feelings of enjoyment and self-identification with the activity reflect functional commitment which is adaptive, whereas social pressures or constraints may lead to a feeling of obligatory commitment which is maladaptive. Weiss and Ferrer-Caja [64] found a higher burnout rate for individuals who reported feeling compelled to continue participating in their sport (i.e., who participated because 'they have to').

In relating these general studies on motivation and commitment in sport to older persons, it could be argued that socio-cultural pressure, such as current health promo- 
tion and its link to 'successful aging', if internalized, can make an older person feel that 'they have to' keep physically, mentally, and socially active in order to 'age well'. Many older people believe that competing in Masters sport is one way they can achieve the goal of aging 'successfully' [21]. For example, the common 'use it or lose it' catch-phrase used by older Masters athletes (discussed above) indicates a desire to use the body and mind as much as possible before one inevitably loses these abilities due to aging. In other words, many older athletes (regardless of when they started or how long they have been competing) simultaneously feel 'they have to' and 'want to' play sport to (a) continue an active, healthy, happy, and engaged life, and (b) avoid ill health, disability, dependency, and isolation in old age $[21,56]$. However, the maintenance of intense physical activity may indicate a denial of existential issues (e.g., self-reflection on the meaning of life, bodily limitations, ill health, and death) which could pose challenges to identity management and development in later life [29, 30].

\section{Challenges age-related stereotypes}

Some researchers have suggested that Masters athletes are important role models for an aging society. Levy and Banaji [65] noted the potential of these 'exemplars' to influence societal attitudes towards the elderly. Indeed, older individuals who accomplish remarkable athletic feats are often profiled in the popular media, which may influence the way that society as a whole views the elderly and the aging process. Less clear, however, is how these aging athletes affect other seniors. Ory et al. [7] suggested that elite-level Masters athletes were likely to intimidate others in the same age cohort, potentially discouraging them from partaking in physical activity. The authors indicated that seniors were most likely to respond positively to images of exercise that included social interaction (i.e., seniors out for a walk with friends) and featured ordinary people doing ordinary things. Subsequent research by Horton and colleagues [66] adds some complexity to these assertions. Qualitative interviews with seniors investigated their reactions to an elite Masters level runner. Reactions fell into three distinct groups: (a) those who found his example inspirational, (b) those who thought that he might be inspirational for a certain group of seniors who were already moderately active, and (c) those who found his example distinctly unappealing.

Generally speaking, there was a slight tendency for participants who reported more daily physical activity in their own lives to categorize the elite athlete as an appropriate role model for seniors. There were, however, exceptions to this - sedentary participants who considered him inspirational, and active participants who did not. In fact, one participant, who reported walking $2 \mathrm{~h}$ per day and working out with weights on a daily basis, considered the image of the elite athlete to be distinctly unappealing: "I look at him as an aberration. I mean... to look at the picture to me is almost stressful to look at. No, that doesn't do anything for me. It turns me right off." Further examination of how seniors react to exemplars of physical fitness from their own age group is an intriguing area of future research, particularly considering current demographic trends, the prevalence of sedentary lifestyles in older populations, and the health consequences of such lifestyles [7].

\section{Limitations of current knowledge and directions for future research}

The discussion above regarding Masters athletes' deconstruction of aging stereotypes reinforces how little we know about the role of sport in the lives of older persons. Furthermore, much of the information presented in this discussion paper is drawn from research in indirectly related areas. More to the point, almost none of the research presented comes from empirical studies explicitly designed to test the primary postulation driving this paper-the potential for participation in sport to provide older adults with beneficial qualities that can be used to improve the quality of their aging experience. If we return to the conception of Lerner et al. [39] of the 5 C's (competence, character, connection, confidence, and caring and compassion), and Benson and colleagues' notion of developmental assets [33], it is likely that sport participation facilitates the development of similar attributes in older persons. Although the specific assets change, existing research suggests that the type of external and internal assets developed through sport participation may be similar. Table 1 presents a proposed modification to Benson's framework, which could become the basis for future work in this area. For example, older adults may feel particularly supported by family and friends (external asset) and challenged to further enhance their abilities and skills (internal asset) through their engagement in Masters sport programs. Furthermore, older people may believe that maintaining health and fitness through sport participation is a constructive use of their time (external asset) that provides them with a sense of personal empowerment (internal asset). On a broader spectrum, moving forward requires addressing two key questions, which we consider below.

Question 1-are there benefits from sport participation that do not come from general physical activity involvement?

Generally, previous research suggests that higher doses of physical activity are associated with improved health. For 
Table 1 Examples of potential assets developed in older sport participants

\begin{tabular}{ll}
\hline Asset type & Examples \\
\hline $\begin{array}{l}\text { External assets } \\
\text { Support }\end{array}$ & $\begin{array}{l}\text { Presence of social support from family members and friends } \\
\text { Empowerment }\end{array}$ \\
Empowered by those around them, reinforcement of positive attitudes towards older persons \\
Constructive use of time & Encouragement from those around them to do well, has friends that model positive behavior \\
Internal assets & Limited time spent 'unengaged' with life, time spent in productive activities \\
Commitment to learning & \\
Positive values & Continued challenge of current abilities and skills \\
Social competencies & Continued reinforcement of concepts of fair play, sportspersonship, etc. \\
Positive identity & Continued development and reinforcement of empathy, sensitivity and friendship skills \\
\hline
\end{tabular}

example, greater rates of physical activity are related to decreased sick days at work [67], lower rates of cardiovascular disease [68], and reduced total adiposity [69]. At present, it is unclear whether the benefits afforded to older adults described in this paper are related to participation in sport or simply a by-product of engagement in physical activity. Moreover, existing studies that have examined the relationship between physical activity and health outcomes have typically examined only single dimensions of health (e.g., physical or psychological health; [70, 71]) and have not considered individuals at the highest end of the physical activity involvement continuum (e.g., Masters athletes) as a separate group. As a result, we have little understanding of how the extreme approach to physical activity associated with Masters athletes' participation may affect health outcomes. Further research is necessary with study designs utilizing highly athletic (i.e., Masters athletes) versus recreationally active older adults (i.e., who meet regular physical activity guidelines) versus non-active older adults. The recent qualitative research on older athletes [e.g., [12, 57, 58]] has indicated the importance of competition, performance, and training in offering unique benefits (e.g., enjoying winning and breaking records, appreciating the medals, recognition, and status, being able to constantly monitor and test performance levels in comparison to one's previous standards, and/ or others of a similar or a significantly younger age). These perceived benefits from sport participation seem to go beyond what is commonly derived from physical activity, further reinforcing the need for more work in this area.

Question 2-are there negative consequences of sport participation in older adults?

As previously outlined, there is a growing body of research that suggests numerous negative experiences and outcomes are associated with youth sport settings [44, 46]. Potential negative experiences and outcomes of sport participation in older adults should also be examined. For example, there is mounting evidence that the dose-response relationship between physical activity and health outcomes is not linear. Excessive aerobic training is associated with increased risk of overuse injuries [72] and immune system dysfunction [73]. Moreover, 'exercise abuse' [74, 75] is a growing area of concern among researchers and medical practitioners. The dose-response relationship between physical activity involvement and health benefits may vary depending on the health outcome under consideration.

Moreover, there is a fine line between pursuing large amounts of physical activity because of one's passion for sport and desire for a healthy lifestyle, and engaging in too much because of one's obsession with physical training or (in the case of older persons) feeling 'they have to' keep active to age successfully. Vallerand and colleagues [76, 77] found that individuals can have two distinct types of passion. Obsessive passion refers to controlled internalization that creates internal pressure to engage in the activity. For example, an athlete with an obsessive passion for running would report having no choice but to attend a scheduled running workout. Harmonious passion refers to an autonomous internalization that leads one to choose to engage in the activity. An athlete with harmonious passion would be able to put aside the workout if the need arises. Their research with adolescent and young-adult athletes suggests that obsessive passion is associated with negative affective and behavioral consequences and that harmonious passion is related to positive consequences. It remains to be seen if this holds true for Masters athletes.

Training occurring over several decades that has become an obsessive pursuit may not be indicative of positive or 'successful' aging. For instance, due to the eventuality of decline and disability commonly associated with a long life, attempting to resist or avoid the aging process by continuing an extremely active lifestyle and physical training can become problematic for an aging identity 
[21], especially if it indicates a denial or avoidance of issues that have to be faced in later life. In particular, when older athletes can no longer participate in sport, some may find it hard to cope [21]. Such an experience may be accompanied by feelings of guilt, shame, and worthlessness. This desire to 'fight aging' also has the potential to (re)produce a heightened fear or undesirability of ill health in old age (both personally and culturally; $[10,78]$ ). The extent to which these potential negative consequences of continued sport participation affect development in later life needs further exploration.

\section{Concluding remarks}

In the sport and exercise psychology field, very little research has been conducted with older participants $[79,80]$. This realization is particularly troubling considering the potential impact of this population on the sustainability of health care systems in many countries [81-83]. This discussion paper is a call to researchers for further work in this area to contribute to our understanding of how physical activity in general, and sport participation in particular, affects development across the lifespan.

An important concern in moving this research forward relates to the hazard of applying frameworks from youth development to older persons. Infantilization of older persons (i.e., relating to an older person as you would a child) is common [84] and has negative consequences for health and wellbeing [85]. As a result, it is paramount that researchers in this area recognize the differences in development as it pertains to younger and older cohorts. Historically, developmentalists have almost exclusively focused on childhood and youth as the primary window of development. The present review extended this discussion to older persons primarily due to the extreme shift in population demographics most industrialized nations are currently experiencing. A central question is whether participation in sport provides desirable outcomes throughout the lifespan that go above and beyond those garnered from simple engagement in general physical activity. Future work in this area will inform public health messaging regarding involvement in sport and physical activity at all ages.

\section{References}

1. Oeppen J, Vaupel JW (2002) Broken limits to life expectancy. Science 296:1029-1031

2. Foot DK, Stoffman D (1996) Boom, bust and echo: how to profit from the coming demographic shift. Macfarlane Walter and Ross, Toronto

3. Weir PL, Kerr T, Hodges NJ, Mckay SM, Starkes JL (2002) Master swimmers: how are they different from younger elite swimmers? An examination of practice and performance patterns. J Aging Phys Act 10:41-63

4. Active Australia (2000) The numbers game: a description of organised sport and physical activity participants in Australia. Australian Sports Commission, Canberra

5. Australian Sports Commission \& Department of Veteran Affairs (2001) Older, smarter, fitter, a guide for providers of sport and physical activity programs for older Australians. Australian Sports Commission, Canberra

6. American Association of Retired Persons, American College of Sports Medicine, American Geriatrics Society, The Centers for Disease Control and Prevention, The National Institute on Aging, \& The Robert Wood Johnson Foundation (2001) National blueprint: increasing physical activity among adults age 50 and older. The Robert Wood Johnson Foundation, Princeton

7. Ory M, Hoffman M, Hawkins M, Sanner B, Mockenhaupt R (2003) Challenging aging stereotypes: strategies for creating a more active society. Am J Prev Med 25:164-171

8. Statistics Canada (2005) Canadian Community Health Survey, 2000/01. Retrieved Aug 20, 2007 from http://www.statcan.ca/ english/freepub/82-221-XIE/00502/tables/html/2165.htm

9. World Health Organization (1998) Growing older, staying well: ageing and physical activity in everyday life. Report No. WHO/ HPR/AHE/98.1. World Health Organization

10. Blaikie A (1999) Ageing and popular culture. Cambridge University Press, Cambridge

11. Levy B, Langer E (1994) Aging free from negative stereotypes: successful memory in China and among the American deaf. J Pers Soc Psychol 66:989-997

12. Grant BC (2001) "You're never too old": beliefs about physical activity and playing sport in later life. Ageing Soc 21:777-798

13. Grant BC (2002) Physical activity: not a popular leisure choice in later life. Soc Leis 25:285-302

14. Nosek BA, Banaji MR, Greenwald AG (2002) Harvesting implicit group attitudes and beliefs from a demonstration web site. Group Dyn 6:101-113

15. Levy BR, Myers LM (2004) Preventive health behaviours influences by self-perceptions of aging. Prev Med 39:625-629

16. O'Brien Cousins S (1995) Anticipated exertion for exercise activities among women over age 70. Can Women's Stud J 15:73-77

17. O'Brien Cousins S (2000) 'My heart couldn't take it': older women's beliefs about exercise benefits and risks. J Gerontol B Psychol Sci Soc Sci 55B:283-294

18. Vertinsky P (1995) Stereotypes of aging women and exercise: a historical perspective. J Aging Phys Act 3:223-237

19. Starkes JL, Weir PL, Young B (2003) What does it take for older expert athletes to continue to excel? In: Starkes JL, Ericsson KA (eds) Expert performance in sport. Human Kinetics, Windsor, pp 251-272

20. Brookes A (2005) Ed Whitlock has resounding victory in Rotterdam with another sub-3: 1-0 Canada! Retrieved on October 14th, 2006 from http://www.torontowaterfrontmarathon.com/en/ news/Apr_11b_05.htm

21. Dionigi RA (2008) Competing for life: older people, sport and ageing. Saarbrüecken, VDM Dr. Müller, Germany

22. Dionigi RA (2006) Competitive sport and aging: the need for qualitative sociological research. J Aging Phys Act 14:365-379

23. Taylor CB, Sallis JF, Needle R (1985) The relation of physical activity and exercise to mental health. Pub Health Rep 100:195202

24. Fraser-Thomas J, Côté J, Deakin J (2005) Youth sport programs: an avenue to foster positive youth development. Phys Ed Sport Pedagogy 10:19-40

25. Snyder CR, Lopez SJ (2005) Handbook of positive psychology. Oxford University Press, Oxford 
26. Holt NL (2007) Positive youth development through sport. Routledge, New York

27. Godbey G (1997) Leisure and leisure services in the 21st century. Venture Publishing, State College

28. Coakley J (2007) Sports in society: issues and controversies, 9th edn. McGraw-Hill, New York

29. Biggs S (1997) Choosing not to be old? Masks, bodies and identity management in later life. Ageing Soc 17:553-570

30. Kleiber DA (1999) Leisure experience and human development: a dialectical approach. Basic, New York

31. Dionigi RA (2002) Leisure and identity management in later life: understanding competitive sport participation among older adults. World Leis J 44:4-15

32. Phoenix C, Sparkes A (2009) Being Fred: big stories, small stories and the accomplishment of a positive ageing identity. Qual Res 9:219-236

33. Benson PL (1997) All kids are our kids: what communities must do to raise caring and responsible children and adolescents. Jossey-Bass, San Francisco

34. Pittman KJ (1991) Promoting youth development: strengthening the role of youth serving and community organizations. Academy for Educational Development, Center for Youth Development and Policy Research, Washington

35. Larson RW (2000) Toward a psychology of positive youth development. Am Psychol 55:170-183

36. Larson RW, Verma S (1999) How children and adolescents spent time across the world: work, play, and developmental opportunities. Psychol Bull 125:701-736

37. Eccles JS, Barber BL (1999) Student council, volunteering, basketball, or marching band: what kind of extracurricular involvement matters? J Adolesc Res 14:10-43

38. Shields DL, Bredemeier BL (2007) Advances in sport morality research. In: Tenenbaum G, Eklund RC (eds) Handbook of sport psychology, 3rd edn. Wiley, Hoboken, pp 662-684

39. Lerner RM, Fisher CB, Weinberg RA (2000) Toward a science for and of the people: promoting civil society through the application of developmental science. Child Dev 71:11-20

40. Benson PL, Leffert N, Scales PC, Blyth DA (1998) Beyond the "village" rhetoric: creating healthy communities for children and adolescents. Appl Dev Sci 2:138-159

41. Leffert N, Benson P, Scales P, Sharma A, Drake D, Blyth D (1998) Developmental assets: measurement and prediction of risk behaviors among adolescents. Appl Dev Sci 2:209-230

42. Scales P, Benson P, Leffert N, Blyth DA (2000) Contribution of developmental assets to the prediction of thriving among adolescents. Appl Dev Sci 4:27-46

43. Scales P, Leffert N (1999) Developmental assets: a synthesis of the scientific research on adolescent development. Search Institute, Minneapolis

44. Fraser-Thomas J, Côté J (2009) Understanding adolescents' positive and negative developmental experiences in sport. Sport Psychol 23:3-23

45. Dworkin JB, Larson R (2006) Adolescents' negative experiences in organized youth activities. J Youth Dev 1:3

46. Dworkin JB, Larson R, Hansen D (2003) Adolescents' accounts of growth experiences in youth activities. J Youth Adolesc 32:1726

47. Hansen DM, Larson R (2005) The youth experience survey 2.0: instrument revisions and validity testing, Unpublished manuscript, University of Illinois at Urbana-Champaign

48. Hansen DM, Larson RW, Dworkin JB (2003) What adolescents learn in organized youth activities: a survey of self-reported developmental experiences. J Res Adolesc 13:25-55

49. Baker J, Horton S, Pearce W, Deakin J (2007) Maintenance of skilled performance with age: a descriptive examination of professional golfers. J Aging Phys Act 15:300-317
50. Starkes JL, Weir PL, Singh P, Hodges NJ, Kerr T (1999) Aging and the retention of sport expertise. Int J Sport Psychol 30:283301

51. Hagberg JM, Allen WK, Seals DR, Hurley BF, Ehsani AA, Holloszy JO (1985) A hemodynamic comparison of young and older endurance athletes during exercise. J Appl Physiol 58:20412046

52. Eskurza I, Donato AJ, Moreau KL, Seals DR, Tanaka H (2002) Changes in maximal aerobic capacity with age in endurance-trained women: 7-yr follow-up. J Appl Physiol 92: 2303-2308

53. Hawkins SA, Marcell TJ, Jaque V, Wiswell RA (2001) A longitudinal assessment of change in $\mathrm{VO}_{2}$ max and maximal heart rate in master athletes. Med Sci Sports Exerc 33:1744-1750

54. Pimentel AE, Gentile CL, Tanaka H, Seals DR, Gates PE (2003) Greater rate of decline in maximal aerobic capacity with age in endurance-trained than in sedentary men. J Appl Physiol 94:2406-2413

55. Pollock ML, Foster C, Knapp D, Rod JL, Schmidt DH (1987) Effect of age and training on aerobic capacity and body composition of master athletes. J Appl Physiol 62:725-731

56. Dionigi RA (2006) Competitive sport as leisure in later life: negotiations, discourse and aging. Leis Sci 28:181-196

57. Dionigi RA (2005) A leisure pursuit that 'goes against the grain': older people and competitive sport. Ann Leis Res 8:1-22

58. Roper EA, Molnar DJ, Wrisberg CA (2003) No "old fool": 88 years old and still running. J Aging Phys Act 11:370-387

59. Bortz WM (1982) Disuse and aging. JAMA 248:1203-1208

60. Wilson RC, Sullivan PJ, Myers ND, Feltz DL (2004) Sources of sport confidence of master athletes. J Sport Ex Psychol 26:369384

61. Routledge R, Medic N, Starkes JL, Weir P, Baker J (2007) Lifelong commitment to sport: modeling from masters marathon runners. Manuscript submitted for publication

62. Ryan RM, Deci EL (2000) Intrinsic and extrinsic motivations: classic definitions and new directions. Contemp Educ Psychol 25:54-67

63. Scanlan TK, Carpenter PJ, Schmidt GW, Simons JP, Keeler B (1993) An introduction to the sport commitment model. J Sport Exerc Psychol 15:1-15

64. Weiss MR, Ferrer-Caja E (2002) Motivational orientations and sport behaviour. In: Horn TS (ed) Advances in sport psychology, 2nd edn. Human Kinetics, Champaign, pp 162-170

65. Levy BR, Banaji MR (2002) Implicit ageism. In: Nelson TD (ed) Ageism: stereotyping and prejudice against older persons. MIT Press, Cambridge, pp 27-48

66. Horton S, Baker J, Côté J, Deakin JM (2008) Understanding seniors' perceptions and stereotypes of aging. Ed Gerontol 34:997-1017

67. Proper KI, van den Heuvel SG, De Vroome EM, Hildebrandt VH, Van der Beek AJ (2006) Dose-response relation between physical activity and sick leave. Br J Sports Med 40:173-178

68. Wannamethee SG, Shaper AG (2002) Physical activity and cardiovascular disease. Semin Vasc Med 2:257-266

69. Ross R, Janssen I (2001) Physical activity, total and region obesity: dose-response considerations. Med Sci Sports Exerc 33: S521-S527

70. Okazaki K, Iwasaki K, Prasad A, Palmer MD, Martini ER et al (2005) Dose-response relationship of endurance training for autonomic circulatory control in healthy seniors. J Appl Physiol 99:1041-1049

71. Netz Y, Wu MJ, Becker BJ, Tenenbaum G (2005) Physical activity and psychological well-being in advanced age: a metaanalysis of intervention studies. Psychol Aging 20:272-284

72. Jones BH, Cowan DN, Knapik JJ (1994) Exercise, training and injuries. Sports Med 18:202-214 
73. Shephard RJ, Rhind S, Shek PN (1994) Exercise and the immune system. Natural killer cells, interleukins and related responses. Sports Med 18:340-369

74. Calogero RM, Pedrotty K (2001) The practice and process of healthy exercise: an investigation of the treatment of exercise abuse in women with eating disorders. Eat Disord J Treat Prevent $12: 273-291$

75. Davis C (2000) Exercise abuse. Int J Sport Psychol 31:278-289

76. Vallerand RJ, Blanchard CM, Mageau GA, Koestner R, Ratelle C, Léonard M, Gagné M, Marsolais J (2003) Les passions de l'âme: on obsessive and harmonious passion. J Pers Soc Psychol 85:756767

77. Vallerand RJ, O'Connor BP, Hamel M (1995) Motivation in later life: theory and assessment. Int $\mathrm{J}$ Aging Hum Dev $41: 221-238$

78. Gilleard C, Higgs P (2000) Cultures of ageing: self, citizen and the body. Prentice Hall, Harlow
79. Biddle SJH (1997) Current trends in sport and exercise psychology research. Psychol Bull Br Psychol Soc 10:63-69

80. Stathi A, Fox KR, McKenna J (2002) Physical activity and the dimensions of subjective well-being in older adults. J Aging Phys Act 10:76-92

81. Kolt GS, Driver RP, Giles LC (2004) Why older Australians participate in exercise and sport. J Aging Phys Act 11:185-198

82. World Health Organization (2002) Active ageing: a policy framework. Report No. WHO/NMH/NPH/02.8. World Health Organization

83. McCormack J (2000) Looking back and moving forward? Ageing in Australia 2000. Ageing Soc 20:623-631

84. Salari SM (2005) Infantilization as elder mistreatment: evidence from five adult day centers. J Elder Abuse Negl 17:53-91

85. Horton S, Baker J, Deakin J (2007) Stereotypes of aging: their effects on the health of seniors in North American society. Educ Gerontol 33:1-15 